Recent Advances

\title{
Dermatology
}

\author{
Mark H Lowitt, Nancy Ryan Lowitt
}

Recent advances in dermatology and related fields have brought new answers to some old questions and new treatment options for some traditionally vexing diseases of the skin. This review focuses on several important reports of the past year, including progress in the understanding of pathogenesis, prevention, diagnosis, and treatment of some of the most difficult dermatologic maladies.

\section{Kaposi's sarcoma}

Since the discovery of its association with human immunodeficiency virus infection, Kaposi's sarcoma (fig 1) has remained one of the most puzzling entities in the cutaneous repertoire of patients infected with HIV. An exhausting array of potential aetiological agents has been proposed.' Until recently, even the basic categorisation of the condition (malignancy, reactive process, infection) has remained uncertain. Reports of Kaposi's sarcoma in homosexual men negative for HIV, ${ }^{2}$ coupled with the observation that among patients positive for HIV Kaposi's sarcoma was more common in homosexual men than in injecting drug users, ${ }^{3}$ led to the suspicion that the condition was sexually transmitted, presumably by a virus distinct from but often transmitted with HIV.

During the past year, several reports have emerged documenting the discovery of herpesvirus-like DNA sequences within Kaposi's sarcoma lesions. ${ }^{46}$ The DNA sequences (sometimes referred to as $\mathrm{KS} 330$ (233) or KSHV) have been identified by polymerase chain reaction and by Southern blot hybridisation. These bits of DNA have been discovered in tissue from the lesions of patients with epidemic (HIV associated) Kaposi's sarcoma as well as classic Kaposi's sarcoma (on the legs of immunocompetent elderly men of Mediterranean descent) and African endemic Kaposi's

Department of

Dermatology, University of Maryland School of Medicine, 405 W Redwood St, Baltimore, $M D$ 21201-1703, USA Mark H Lowitt, assistant professor

Division of General Internal Medicine, Johns Hopkins Bayview Medical Center, Baltimore, MD 2122, USA

Nancy Ryan Lowitt, instructor

Correspondence to: DrM H Lowitt.

$B M 7$ 1995;311:1615-7 sarcoma. ${ }^{5}$ The additional finding of similar sequences in tissue from some lymphomas in patients infected with $\mathrm{HIV}^{7}$ and in Kaposi's sarcoma from homosexual men negative for $\mathrm{HIV}^{6}$ lends support to the hypothesis that a novel group of herpesviruses may be the major aetiological agent of all forms of Kaposi's sarcoma as well as some lymphomas in the immunocompromised host.

\section{Varicella vaccine}

One of the time honoured scourges of the playground, varicella (chickenpox), is now threatened by the development of a live attenuated varicella vaccine. Although varicella is usually a benign affliction, characterised by a miserably pruritic child and a temporarily housebound parent, infection with varicella zoster virus may infrequently lead to severe

\section{Recent advances in dermatology}

Infectious disease

- Herpesvirus-like sequences are associated with Kaposi's sarcoma

- A live attenuated vaccine is now recommended for prevention of varicella zoster virus infection

\section{Inflammatory dermatoses}

- Topical calcipotriol is effective in treatment of psoriasis

- Topical doxepin is effective in treatment of atopic dermatitis

- An autoimmune mast cell mechanism is proposed for chronic urticaria

Cutaneous neoplasms

- A candidate gene for the familial atypical molemelanoma syndrome may be the growth regulator p16 on chromosome 9

- Tumour thickness, level of invasion, sex, and anatomic location are independent prognostic factors in survival with melanoma

sequelae such as pneumonitis, encephalitis, and even death, particularly when acquired in adulthood or by immunocompromised individuals. Arguments for and against universal vaccination have raged, alternately citing the rare but serious risks of the disease, the loss of parental productivity in the workplace, the high prevalence of infection, and the possible eradication of herpes zoster infections-against the high costs of widespread vaccination, generally trivial nature of the illness, uncertain long term degrees of immunity from the vaccine, and risks to unvaccinated individuals who might tend to acquire the infection later in life when the danger of serious sequelae would be greater. After healthy debate, the American Academy of Pediatrics has recently adopted a position in support of universal vaccination of healthy non-immune children and adults. $^{8}$

\section{Topical calcipotriol for psoriasis}

Topical calcipotriol (vitamin D3) ointment is a new treatment for psoriasis with great promise. Several studies have confirmed the effectiveness of this agent in the treatment of moderate plaque-type psoriasis (fig 2). ${ }^{9-12}$ Although its mechanism of action is not entirely understood, vitamin D3 is known to act locally to increase extracellular calcium concentrations, which leads to increased keratinocyte differentiation and decreased proliferation and scaling. Topical calcipotriol has been found to be superior in the treatment of 


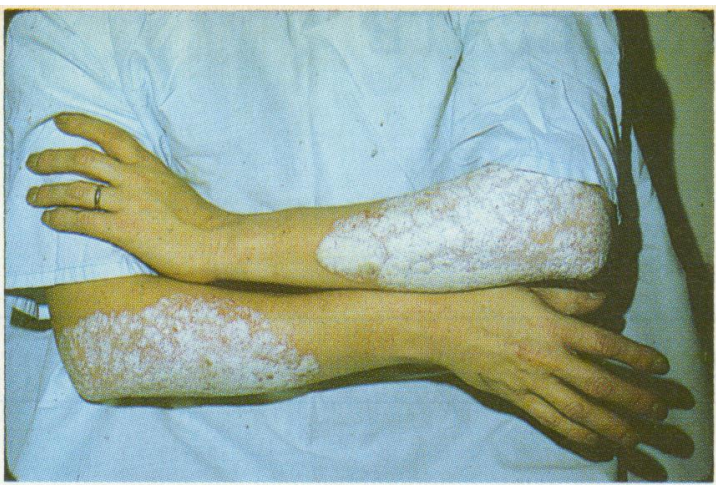

Fig 2-Chronic plague-type psoriasis

chronic plaque-type psoriasis in comparison with placebo, ${ }^{910} 15 \%$ coal tar, ${ }^{11}$ and topical clobetasol propionate $0.05 \% .{ }^{12}$ With the exception of rare skin irritation, calcipotriol ointment was well tolerated, effective, and safe. Monitoring of serum calcium concentration may be appropriate in selected patients with known or suspected baseline hypercalcaemia. Topical calcipotriol is a welcome addition to the palette of antipsoriatic drugs because it is effective and an excellent alternative to topical steroids.

\section{Topical doxepin for atopic dermatitis}

The degree of disfigurement and debilitation caused by the pruritus of atopic dermatitis cannot be overestimated. Although topical steroids, emollients, and oral antihistaminic agents are often of great benefit, many patients suffer from intractable itch. Ultraviolet treatment, cyclosporine, and systemic corticosteroids, while effective for some patients, are impractical, ineffective, or unsafe in the long term for many others. Because of its antihistaminic activity (both $\mathrm{H}_{1}$ and $\mathrm{H}_{2}$ ) and its efficacy in the treatment of itch when taken orally, a topical formulation of doxepin, the tricyclic antidepressant, has been introduced. When administered in a placebo controlled, double blind fashion to 270 patients with active atopic dermatitis, doxepin $5 \%$ ointment gave significantly greater relief of itch than did the vehicle alone. ${ }^{13}$ Mild localised burning (30\%) and mild drowsiness during the first three days of treatment $(28 \%)$ were the most common adverse effects in the group treated with doxepin.

\section{Pathogenesis of chronic urticaria}

Physicians and patients alike dread the diagnosis of chronic urticaria (hives) in light of its persistence, association with life threatening angio-oedema, erratic response to treatment, and infrequent identification of a causative factor. After exclusion of physical causes of urticaria (cold, pressure, sunlight, heat, water), drugs (particularly aspirin and nonsteroidal antiinflammatories), foods, infections (hepatitis, chronic sinusitis), and autoimmune connective tissue disease, the remaining majority of patients are relegated to the "idiopathic" category. ${ }^{14}$

New information may now help to identify a subset of urticaria sufferers whose condition may actually represent a form of autoimmune mast cell disease. ${ }^{14}{ }^{15}$ An IgG autoantibody with the ability to bind and cross link IgE receptors on mast cells has been identified in the serum of some patients with chronic urticaria. In one study, 98 of 163 patients $(60 \%)$ with chronic urticaria developed wheals after intradermal injection of their own (autologous) serum. These same samples were able to elicit the release of histamine from basophils of healthy controls. The chronic production of these autoantibodies may therefore explain the long term nature of the illness. Experimental treatments with plasmapheresis, intravenous immunoglobulin, and cyclosporin have been effective in a small number of patients. This exciting new finding may shed light on and lead to further understanding of this heretofore unexplained condition.

\section{Familial atypical mole-melanoma gene}

The hunt for the genetic basis of the familial syndrome of atypical moles and malignant melanoma has advanced rapidly in the past several years. After the initial observations that people with many large atypical moles had an increased risk of melanoma, the name for this syndrome has varied; names including dysplastic nevus syndrome, familial atypical mole and melanoma syndrome (FAMMM), and B-K mole syndrome.

Early evidence pointed towards a locus on the short arm of chromosome 1, but several other possible sites had been identified. Some recent studies point towards an area on the short arm of chromosome $9 .{ }^{16}$ Within this chromosomal segment $(9 \mathrm{p} 21)$ resides p16, a gene which codes for a protein that regulates cell replication. ${ }^{16}$ The normal protein product of this gene inhibits mitosis and DNA synthesis, maintaining a baseline inhibitory tone in cells by blocking progression of the cell cycle. A mutation or deletion of the inhibitory p16 gene therefore results in uncontrolled cellular replication and consequent neoplasia. Deletions in the $\mathrm{p} 16$ gene have been identified in a wide spectrum of malignancies.

In studies of some families prone to melanoma, uniform deletions in the gene have been detected among affected members. ${ }^{17}$ As this abnormality is not present in many other kindreds prone to melanoma, ${ }^{17}$ investigation will need to continue in the search for other genes or regulators involved in the genetic predisposition to melanoma. Taken in sum, however, these early data promise much for our future understanding of the genetic basis for this deadly cutaneous neoplasm.

\section{Prognostic factors in malignant melanoma}

Since the pioneering work of Clark and Breslow, the depth of dermal invasion by melanoma cells has been considered to be the most important prognostic factor in long term survival for patients with this disease. Two recent large studies conclude that some additional factors may prove to be independent predictive factors in survival. ${ }^{18} 19$ In an 18 year follow up of 5264 patients with primary cutaneous melanoma (fig 3), four independently significant prognostic factors were found: tumour thickness, level of invasion, sex, and anatomic location (table). As expected, Breslow tumour thickness was the most powerful prognostic factor for 10 year survival. Tumours with thicknesses of from $1.01-2.0 \mathrm{~mm}$ and $2.01-4.0 \mathrm{~mm}$ portended a much higher risk of death than those of $1.00 \mathrm{~mm}$ or less. The Clarks level (a classification based on the anatomic level of the skin to which the tumour cells extend) proved to be an independent variable, distinguishing particularly between patients with level II disease (full involvement of the papillary dermis) and those with level III or greater (extension into or deeper than the reticular dermis). This finding may be a blow for patients with melanomas on areas of particularly thin skin, where the Breslow thickness may be thin but the anatomic depth of invasion is greater. Men were found to have a greater relative risk of 10 year mortality than women, independent of other variables such as tumour thickness. The anatomical location of the tumour was also important in prognosis: melanomas in the "TANS" areas (thorax, upper arms, neck, and scalp) showed a higher relative risk. Although more 
Prognosis of primary cutaneous melanoma (from Garbe et $a^{19}$ ). Reprinted by permission of Lippincott-Raven Publishers

\begin{tabular}{|c|c|c|}
\hline Prognostic factor & $\begin{array}{l}\text { Relative } \\
\text { risk (95\% } \\
\text { confidence } \\
\text { interval) }\end{array}$ & P value \\
\hline \multicolumn{3}{|l|}{ Tumour thickness: } \\
\hline $\begin{array}{l}>1 \mathrm{~mm} v \leqslant 1.00 \mathrm{~mm} \\
>2 \mathrm{~mm} v 1.01-2.00 \mathrm{~mm} \\
<4 \mathrm{~mm} v 42.01-4.00 \mathrm{~mm}\end{array}$ & $\begin{array}{l}2.6(1.8-3.8) \\
2.7(2.2-3.4) \\
1.6(1.4-2.0)\end{array}$ & $\begin{array}{l}>0.0001 \\
<0.0001 \\
<0.0001\end{array}$ \\
\hline $\begin{array}{l}\text { Level of invasion: } \\
\quad \geqslant\|\| v \|\end{array}$ & $4.0(2 \cdot 0-8 \cdot 1)$ & $<0.0001$ \\
\hline $\begin{array}{l}\text { Sex: } \\
\text { Male vfemale }\end{array}$ & $1.5(1.3-1.8)$ & $<0.0001$ \\
\hline $\begin{array}{l}\text { Anatomical location: } \\
\text { TANS } v \text { non-TANS }\end{array}$ & $1.6(1.4-1.8)$ & $<0.0001$ \\
\hline $\begin{array}{l}\text { Histological subtype: } \\
\text { ALM vSSM or LMM } \\
\text { NM v SSM or LMM }\end{array}$ & $\begin{array}{c}1.7(1.2-12.3) \\
1.2(1.0-1.4)\end{array}$ & $\begin{array}{l}<0.01 \\
<0.05\end{array}$ \\
\hline Age:* & & \\
\hline $\begin{array}{l}>60 \text { years } v \leqslant 60 \text { years } \\
\text { Year of diagnosist } \\
\text { Safety margin: }\end{array}$ & $1.2(1.0-1.4)$ & $\begin{array}{r}0.05 \\
\text { NS }\end{array}$ \\
\hline$<2 \mathrm{~cm} v \geqslant 2 \mathrm{~cm}$ & & NS \\
\hline
\end{tabular}

TANS=thorax, upper arm, neck, and scalp; ALM=acral lentiginous melanoma; SSM=superficial spreading melanoma; $L M M=$ lentigo maligna melanoma; $\mathrm{NM}=$ nodular melanoma; $\mathrm{NS}=$ not significant. Results are adjusted for the effects of the participating centres. *Classification of age: $\leqslant 30$ years; $31-60$ years; $>60$ years.

tClassification of year of diagnosis: 1970-5; 1976-80; 1981-5; $\geqslant 1986$.

confirmatory studies are needed, these data may allow physicians to provide more accurate information on survival to their patients with melanoma.

Funding: None.

Conflict of interest: None.
1 Tappero JW, Conant MA, Wolfe SF, Berger TG. Kaposi's sarcoma. I Am Acad Dermatol 1993;28:371-95.

2 Friedman-Kien AE, Saltzman BR, Cao YZ, Nestor MS, Mirabile M, Li JJ, et al. Kaposi's sarcoma in HIV-negative homosexual men. Lancet 1990;335: $168-9$.

3 Beral V, Peterman TA, Berkelman RL, Jaffe HW. Kaposi's sarcoma among persons with AIDS: a sexually transmitted infection? Lancet 1990;335: 123-8.

4 Chang Y, Cesarman E, Pessin MS, Le F, Culpepper J, Knowles DM, et al. Identification of herpesvirus-like DNA sequences in AIDS associated Kaposi's sarcoma. Science 1994;266:1865-9.

5 Huang YQ Li J, Kaplan MH, Poiesz B, Katabira E, Zhang WC, et al. Human herpesvirus-like nucleic acid in various forms of Kaposi's sarcoma. Lancet 1995;345:759-61.

6 Moore PS, Chang Y. Detection of herpesvirus-like DNA sequences in Kaposi's sarcoma in patients with and without HIV infection. $N$ Engl 9 Med 1995;332:1181-5.

7 Cesarman E, Chang Y, Moore PS, Said JW, Knowles DM. Kaposi's sarcomaassociated herpesvirus-like DNA sequences in AIDS-related body-cavitybased lymphomas. N Engl \% Med 1995;332:1186-91.

8 Recommendations for the use of live attenuated varicella vaccine. American Academy of Pediatric Committee on Infectious Diseases. Pediatrics 1995;95: 791-6.

9 Ramsay CA, Berth-Jones J, Brundin G, Cunliffe WJ, Dubertret L, van de Kerkhof, et al. Long-term use of topical calcipotriol in chronic plaque psoriasis. Dermatology 1994;189:260-4.

10 Highton A, Quell J. Calcipotriene ointment $0.05 \%$ for psoriasis: a safety and efficacy study. $₹$ Am Acad Dermatol 1995;32:67-72.

11 Than SN, Lun KC, Cheong WK. A comparative study of calcipotriol ointment and tar in chronic plaque psoriasis. Br $\mathcal{F}$ Dermatol 1994;131:673-7.

12 Berardesca E, Vignoli GP, Farinelli N, Vignini M, Distante F, Rabbiosi G. Non-invasive evaluation of topical calcipotriol versus clobetasol in the treatment of psoriasis. Acta Dermatol Venereol 1994;74:302-4.

13 Drake IA, Fallon JD, Sober A. Relief of pruritus in patients with atopic dermatitis after treatment with topical doxepln cream. $\Im$ Am Acad Dermatol dermatitis after

14 Greaves MW. Chronic urticaria NEnglg Med 1995:332:1767-72.

15 Hide M, Francis DM, Grattan CE, Barr RM, Winkelmann RK, Greaves MW. The pathogenesis of chronic idiopathic urticaria new evidence suggests an auto-immune basis and implications for treatment. Clin Exp All 1994;24: 624-7.

16 Cannon-Albright LA, Goldgar DE, Meyer LJ, Lewis CM, Anderson DE, Fountain JW, et al. Assignment of a locus for familial melanoma, MLM to chromosome 9p 13-p22. Science 1992;258:1148-52.

17 Kamb A, Shattuck-Eidens D, Eeles R, Liu Q Gruis NA, Ding W, et al. Analysis of the p16 gene (CDKN2) as a candidate for the chromosome 9pm melanoma susceptibility locus. Nature Generics 1994:8:22-6.

18 Garbe C, Buttner P, Bertz J, Burg G, d'Hoedt B, Drepper H, et al. Primary cutaneous melanoma. Identification of prognostic groups and estimation of cutaneous melanoma. Identification of prognostic groups and
individual prognosis for 5093 patients. Cancer 1995;75:2484-91.

19 Garbe C, Buttner P, Bertz J, Burg G, d'Hoedt B, Drepper H, et al. Primary cutaneous melanoma. Prognostic classification of anatomic location. Cancer 1995;75:2492-8.

\section{Ethical Debate}

\section{Should doctors be more proactive as advocates for victims of violence?}

Currently the management of adult victims of violence by general practitioners and accident and emergency departments is reactive, concerned almost exclusively with the management of physical injuries. Professor fonathan Shepherd outlines some ideas for a more proactive approach on the part of doctors to improve the protection and support of vulnerable people; to deal with psychological sequelae; to take the responsibility of making an official complaint to the police away from seriously injured people, who are unable to give or withhold consent to disclosure; and to prevent assailants inflicting further injuries. We asked a sociologist, a psychiatrist, a moral philosopher, and a police surgeon for their comments.

\section{Towards interagency procedures to protect victims and prevent violence}

\section{University of Wales College of Medicine, Cardiff CF4 4XY Jonathan Shepherd, professor of oral and maxillofacial surgery}

BMJ 1995;311:1617-21

\section{Jonathan Shepherd}

A public health approach to violence has focused so far on risk factors such as alcohol consumption, ${ }^{1}$ availability of firearms, ${ }^{2}$ and links between deprivation and crime $^{3}$ but has yet to include trying to bring violent offenders to justice. Yet there is now strong evidence of a link between the incidence of violence and the rate at which offenders are convicted. Increasing the rate of conviction is therefore likely to be an effective way to prevent injury.

Criminal justice and public health have much in common. Both use deterrence (health warnings), incapacitation (isolation), and rehabilitation. A public health approach, however, focuses on the injured rather than the offenders. It can therefore be concerned with the very large number of violent incidents on both sides of the Atlantic that are neither reported to nor recorded by the police ${ }^{67}$ In Britain only about a quarter of the assaults resulting in treatment at accident and emergency departments are recorded by the police. ${ }^{8}$

Although criminal law treats all assaults as offences against society, the initiation and maintenance of the prosecution process depends on the injured themselves. ${ }^{9}$ Many of these people are repeatedly injured by assailants in whose "web of power" they are trapped.". This applies not just to women who are injured in domestic violence but to many other people..$^{9}$ Many victims do not report violence or make complaints that trigger police action because they are incapacitated by their injuries, afraid of reprisals, habituated to violence, or have a continuing relationship with their assailants. Furthermore, because the police judge that many victims who report offences will drop the 